\title{
Field, laboratory and estimated soil-water content limits
}

\author{
Mussie F Gebregiorgis and Michael J Savage* \\ Soil-Plant-Atmosphere Continuum Research Unit, School of Environmental Sciences, \\ University of KwaZulu-Natal, Pietermaritzburg, South Africa
}

\begin{abstract}
For the purpose of irrigation scheduling, estimates of soil-water content limits are determined using field or laboratory measurements or empirically-based regression equations. In this study the field method involved measuring simultaneously the soil-water content (using a frequency domain reflectometer with the PR1 profile probe that relies on changes in the dielectric constant of soil), and soil-water potential (using Watermark granular matrix sensors and tensiometers) at three depths (100, 300 and $600 \mathrm{~mm}$ ) from a $1 \mathrm{~m}^{2}$ bare plot. A retentivity relationship was developed from these measurements and the drained upper limit was estimated to be $0.355 \mathrm{~m}^{3} \cdot \mathrm{m}^{-3}$ when the drainage from the pre-wetted surface was negligibly small. The lower limit, corresponding to $-1500 \mathrm{kPa}$, was estimated to be $0.316 \mathrm{~m}^{3} \cdot \mathrm{m}^{-3}$. In the laboratory, soil-water content and soil matric potential were measured on undisturbed soil samples taken from the edge of the bare plot. The undisturbed soil samples were saturated and exposed to different matric potentials between -1 and $-1500 \mathrm{kPa}$. A retentivity relationship was then developed from these measurements. The laboratory method realized a drained upper limit value of $0.390 \mathrm{~m}^{3} \cdot \mathrm{m}^{-3}$ at $-33 \mathrm{kPa}$ and a lower limit value of $0.312 \mathrm{~m}^{3} \cdot \mathrm{m}^{-3}$ at $-1500 \mathrm{kPa}$. A regression equation, which uses the soil bulk density and the clay $(<0.002 \mathrm{~mm})$ and silt $(0.002$ to $0.05 \mathrm{~mm})$ percentage to estimate the soil-water content at a given soil-water potential, realised a drained upper limit value of $0.295 \mathrm{~m}^{3} \cdot \mathrm{m}^{-3}$ at $-33 \mathrm{kPa}$ and a lower limit value $0.210 \mathrm{~m}^{3} \cdot \mathrm{m}^{-3}$ at $-1500 \mathrm{kPa}$. Comparisons were made between field, laboratory and regression equation methods of estimating the upper and lower soil-water content limits. The fieldmeasured soil-water content was statistically different from the laboratory-estimated and regression equation estimates of soil-water content. This was shown from a paired $t$-test, where the probability levels for the laboratory and regression equation methods were 0.011 and 0.0005 respectively at the $95 \%$ level of significance. Field method soil-water content comparisons with the laboratory method resulted in a linear regression coefficient of determination of 0.975 with a root mean square error (RMSE) of $0.064 \mathrm{~m}^{3} \cdot \mathrm{m}^{-3}$. By contrast, field method comparisons with the regression equation method showed a coefficient of determination of 0.995 with an RMSE of $0.035 \mathrm{~m}^{3} \cdot \mathrm{m}^{-3}$. The frequency domain reflectometry method used for monitoring soilwater content has been shown to be useful in this case of relatively homogenous soils supporting perennial crops.
\end{abstract}

Keywords: soil-water content limits, Watermark granular matrix sensor, tensiometer measurements, PR1 soilwater profile probe dielectric method

\section{Introduction}

The field-measurement of soil-water content is of paramount importance in irrigation science and irrigation management. It affects irrigation system design, irrigation system management, crop selection and crop management. There are, however, very few practical field methods for measuring or estimating soilwater content. Accurate measurement of the lower limit and the drained upper limit is required to estimate the available water reserve of a soil and these limits are critical inputs required by soil-water balance models (Ritchie, 1981). Both the lower limit and drained upper limits can be measured in the field or laboratory or they can be estimated using empirical equations based on easily measured soil properties such as soil texture, soil bulk density and soil organic matter content. The field-measured lower limit is taken as the soil-water content at which plants were practically dead or dormant as a result of the soil-water deficit (Ratliff et al., 1983). The lower limit could also be measured using in situ soil psychrometers (Savage et al., 1996). The drained upper limit is taken as the soil-water content at which drainage from a pre-wetted soil practically ceases or when the soil-water content decrease is about 0.001 to $0.002 \mathrm{~m}^{3} \cdot \mathrm{m}^{-3} \cdot \mathrm{d}^{-1}$ (Ratliff et al., 1983).

* To whom all correspondence should be addressed. 兽 +2733 260 5510; fax: +2733 2605514 ; e-mail: savage@ukzn.ac.za Received 21 January 2005; accepted in revised form 1 December 2005.
In the laboratory, the most common procedure for estimating the drained upper limit and lower limit is to extract water from a disturbed or undisturbed soil sample using the soil-water extraction apparatus (Richards and Weaver, 1943). The lower limit is estimated using the apparatus at a soil matric potential of -1500 $\mathrm{kPa}$ (Richards and Weaver, 1943). The water content at a matric potential of $-33 \mathrm{kPa}$ is used as an estimate of the drained upper limit for moderately coarse and fine-textured soils, whereas -10 $\mathrm{kPa}$ is used for coarse-textured soils (Colman, 1947; Jamison and Kroth, 1958).

Field or laboratory measurement of the relationship between soil-water potential and soil-water content is expensive, difficult, and often impractical (Saxton et al., 1986). Thus, for many purposes, general estimation is often based on more readily available information such as soil texture, soil bulk density and soil organic matter, thereby reducing the time and cost of laboratory and field measurements. Many researchers (Brooks and Corey, 1964; Gupta and Larsen, 1979; Mottram et al., 1981; Rawls and Brakensiek, 1982; Cosby et al., 1984; Schulze et al., 1985; Hutson, 1986; Saxton et al., 1986; Ritchie et al., 1999) have developed regression equations to estimate the soil-water potential and water content relationships from soil texture, soil bulk density and soil organic matter. Mottram et al. (1981), for example, developed regression equations for the top- and subsoil of 31 soil types at Mkuzi (KwaZulu-Natal, South Africa) based on the soil texture clay $(<0.002 \mathrm{~mm})$ and silt $(0.002$ to $0.05 \mathrm{~mm}$ ), organic matter and bulk density. The lower limit was estimated at a matric potential of $-1500 \mathrm{kPa}$ and the upper limit 
of plant available water was defined for a matric potential of $-5 \mathrm{kPa}$ as opposed to the normally accepted value of -10 or $-33 \mathrm{kPa}$. This choice supports the findings of MacLean and Yager (1972) in Zambia.

Ratliff et al. (1983) compared field and laboratory measurements of the lower limit and the drained upper limit and found that laboratory estimates of the drained upper limit obtained at a water content corresponding to $-33 \mathrm{kPa}$ were significantly less than field-measured drained upper limits for sands, sandy loams, and sandy clay loams and significantly greater than field estimates for silt loams, silty clay loams, and silty clays. Laboratory estimates of the lower limit corresponding to $-1500 \mathrm{kPa}$ were significantly less than field lower limit measurements for sands, silt loams and sandy clay loams and significantly more than field observations for loams, silty clays, and clays. Ratliff et al. (1983) also suggested that, if accuracy is necessary in soil-water balance calculations, laboratory-estimated soil-water limits should be used with caution and also that field-measured limits are preferred.

Salter and Haworth (1961) also found that the direct method in the field involving soil sampling after irrigation and drainage had almost ceased, gave more accurate and consistent measurements using the soil-water extraction laboratory method. From their results they concluded that for rough estimation of soil-water content limits, the laboratory method using undisturbed soil cores yields satisfactory results, but for more critical work, the use of the direct measurement (field method) is essential using soil-water content or soil-water potential sensors (Lukangu et al., 1999; Gebregiorgis and Savage, 2006; Lukanu and Savage, 2006). An instrument and/or field method for estimating soil-water content or soil-water potential that is practical and sufficiently accurate will be of great benefit.

In this study, three methods for determining the lower and drained upper soil-water content limits were tested and the measurements compared. Field, laboratory and estimated values of soil-water potential and soil-water content values were measured to determine the soil-water content limits.

\section{Materials and methods}

In the field, soil-water content was measured using a PR1 profile probe (Delta-T Devices, Cambridge, UK) which provides measurements at 100, 200,300, 400, 600 and $1000 \mathrm{~mm}$ depths and soil-water potential was measured using tensiometers (Cassel and Klute, 1986) and Watermark granular matrix sensors (Irrometer, Riverside, USA).

The electronics embedded in the PR1 profile probe (dielectric method that uses frequency domain reflectometry), generates a $100 \mathrm{MHz}$ signal. If the dielectric properties of the soil are different from the probe electronics, the reflected signal combines with the generated signal to form a standing wave with an amplitude that is a measure of the soil-water content. The PR1 profile probe contact between soil and sensor is crucial for accurate soil-water measurements and particularly so for soilwater content measurements (Gebregiorgis and Savage, 2006). Currently, there is no measure of whether there is adequate soil contact in any of the soil-water dielectric methods used.

The Watermark sensor is designed to offer the advantage of the tensiometric and gypsum block approaches (Armstrong et al., 1987). The Watermark sensor electrodes are embedded in a non-dissolvable matrix material, and the sensor incorporates an internal gypsum buffer to minimise the effect of salts experienced in irrigated landscapes. The matrix material is held in place by a porous membrane. Watermark sensors are sensitive to salinity and soil temperature and the matrix characteristics of the sensor changes with time (Jovanovic and Annandale, 1997). In the laboratory, the soil-water content and corresponding soilwater potential value were measured at the same time to develop a retentivity relationship. A known pressure was applied using a tension table creating a matric potential between -1 and $-10 \mathrm{kPa}$, pressure pot (-50 and $-100 \mathrm{kPa})$ and pressure chamber at -1500 $\mathrm{kPa}$ and the soil-water content was measured after equilibrium was reached. The empirical equations developed by Hutson (1986) were used to estimate the soil-water content limits. These equations require the clay, silt, fine sand percentages and soil bulk density as an input to estimate the soil-water content at the corresponding matric potential.

For each method, the soil-water content and soil-water potential were related using the retentivity relationship developed by Gardner et al. (1970). In this relationship, the soil-water potential was treated as the independent variable and the soil-water content the dependent variable. The retentivity relationship is expressed by:

$$
\theta=(-\psi / a)^{-1 / b}
$$

where:

$\theta$ is the volumetric soil-water content $\left(\mathrm{m}^{3} \cdot \mathrm{m}^{-3}\right)$ and

$\Psi$ is the soil-water potential $(\mathrm{kPa})$ [where the negative sign in front of $\Psi$ ensures that the exponent may be calculated].

The $a$ and $b$ empirical constants, which can be developed from the regression line of $\ln \theta$ vs. $\ln (-\Psi)$, are given by:

$$
\begin{aligned}
& a=\exp \left(a_{r} b\right) \\
& b=-1 / b_{r}
\end{aligned}
$$

where:

$a_{r}$ and $b_{r}$ are the intercept and slope values of the regression line respectively for the $\ln \theta v s \ln (-\Psi)$ graph fitted by a straight line.

\section{Field measurements}

In the field, inside a $1 \mathrm{~m}^{2}$ bare plot (Photo 1 ), six tensiometers and six Watermark sensors were installed at 100, 300 and $600 \mathrm{~mm}$ soil depths in two replications with all sensors equidistant from a single PR1 profile probe. The depths were chosen to represent the root zones within the cultivated soil and immediately below the depth of cultivation. The tensiometers and the Watermark sensors were installed around the PR1 profile probe within a radius of $200 \mathrm{~mm}$ and $150 \mathrm{~mm}$ apart from each other.

The access tubes of the PR1 profile probe were installed using gouge and spiral augers, taking care to not disturb the soil profile. First, the gouge auger ( $22 \mathrm{~mm}$ diameter) was pushed into the soil to the depth of the blade. The auger was then fully rotated to excavate the soil, and withdrawn while continuing to rotate. When the desired depth was reached, the hole was shaped with the spiral auger ( $25 \mathrm{~mm}$ diameter). The access tube was then pushed into the slightly narrower hole to ensure a tight fit that prevented the creation of air gaps between the access tube and the soil.

The Watermark sensors were soaked in water for two days prior to their installation. In the field, $25 \mathrm{~mm}$ diameter holes were made using the gouge and spiral augers, to the desired depth, and filled with a slurry made from the excavated soil. These procedures ensured a snug fit between sensor and soil. 


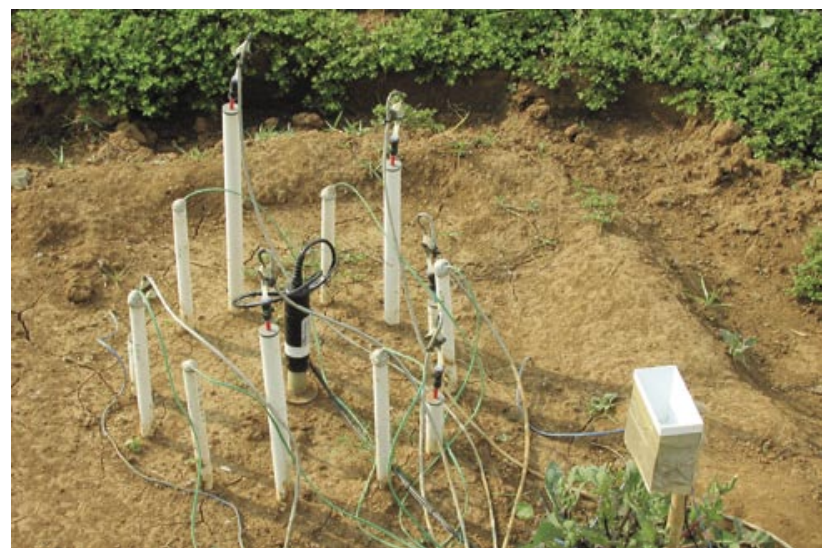

Photo 1

A PR1 profile probe is shown at the centre of a $1 \mathrm{~m}^{2}$ bare plot. Tensiometers and Watermark sensors surround the PR1 profile probe. A Pronamic rain-gauge is shown at the bottom right

The sensors were then pushed with the PVC pipe, which was fitted tightly over the sensor collar until it reached the required depth. The holes were then carefully backfilled and trampled down to prevent air pockets, which could allow water to be channelled to the sensor depth.

The ceramic tips of the tensiometers were saturated for $24 \mathrm{~h}$ in water before installation. In the field, $22 \mathrm{~mm}$ diameter holes were made using the gouge auger and a slurry was poured into the holes. The slurry was made from the excavated soil and ensured a tight fit between sensor and soil. The tensiometers were pushed carefully so that they reached the desired depth. The holes were then backfilled and trampled to prevent channelling of water to the sensor depth.

After all the sensors had been installed, the plot was flooded and covered for two days with black plastic to prevent evaporation and to allow a redistribution of water throughout the soil profile. The soil-water potential Watermark and tensiometer sensors were connected to a CR23X data logger (Campbell Scientific, Logan, USA) and the PR1 profile probe connected to a CR10X data logger programmed to measure the soil-water content every $3 \mathrm{~h}$. The soil-water content vs. soil-water potential relationship was determined from the simultaneous measurement of the PR1 profile probe soil-water content and the soil-water potential sensors (tensiometer and Watermark) while the soil dried. The drained upper limit value was determined after two days when the rate of change in the soil-water content was negligible (Ratliff et al., 1983). The lower limit was also calculated, using the retentivity relationship, as corresponding to a soil-water potential of $-1500 \mathrm{kPa}$, which corresponds closely to the field lower limit of soil-water availability (Savage et al., 1996).

\section{Laboratory measurements}

To determine the retentivity relationship, six undisturbed soil samples were taken $800 \mathrm{~mm}$ away from the position of the sensors, using a core sampler, at the $100,200,300,400,600$, and $1000 \mathrm{~mm}$ soil depths in three replications at the edge of the $1 \mathrm{~m}^{2}$ bare plot prior to the installation of the sensors. This choice of distance between sensor position and sampling site ensured that the disturbance created by sensor installation did not impose on the sphere of influence of the installed sensors. The sphere of influence of the sensors is less than $100 \mathrm{~mm}$ and $100 \mathrm{~mm}$ for the profile probe (Delta-T Devices, 2001). The tensiometer (Cassel and Klute, 1986) and Watermark (Armstrong et al., 1987) sensors

\begin{tabular}{|c|c|}
\hline \multicolumn{2}{|c|}{$\begin{array}{c}\text { TABLE } 1 \\
\text { Regression equations (Eqs. (4) to }(10) \text { ) } \\
\text { developed by Hutson (1986) to estimate the soil- } \\
\text { water content at matric potentials of }-1,-3,-10 \text {, } \\
-30,-100,-500 \text { and }-1500 \mathrm{kPa} \text { respectively }\end{array}$} \\
\hline$\theta_{-1}=0.686+0.000794(C l+S i)-0.229 \rho_{b}$ & 4 \\
\hline$\theta_{-3}=0.349+0.00211(\mathrm{Cl}+\mathrm{Si})-0.096 \rho_{b}$ & 5 \\
\hline$\theta_{-10}=0.112+0.00380(\mathrm{Cl}+\mathrm{Si})$ & 6 \\
\hline$\theta_{-30}=0.065+0.00396(\mathrm{Cl}+\mathrm{Si})$ & 7 \\
\hline$\theta_{-100}=0.038+0.00372(C l+S i)$ & 8 \\
\hline$\theta_{-500}=0.0185+0.00366(\mathrm{Cl}+\mathrm{Si})$ & 9 \\
\hline$\theta_{-1500}=0.0187+0.00337(\mathrm{Cl}+\mathrm{Si})$ & 10 \\
\hline
\end{tabular}

$\theta$ is the volumetric water content in $\mathrm{m}^{3} \cdot \mathrm{m}^{-3},(\mathrm{Cl}+\mathrm{Si})$ is the sum of clay and silt content of the soil in percentage and $\rho_{b}$ is the bulk density of the soil in $\mathrm{Mg} \cdot \mathrm{m}^{-3}$.

equilibrate with the soil-water potential of the neighbouring soil.

After the core samples were taken, they were trimmed carefully to the edge of the sleeve and saturated in a water bath by capillary action. After the cores were totally saturated, they were weighed while water was dripping to obtain the saturation weight and transferred to a tension table where a hanging water column was used to create a matric potential between -1 and $-10 \mathrm{kPa}$, a pressure pot was used for matric potentials between -50 and $-100 \mathrm{kPa}$ and a pressure chamber for a matric potential at $-1500 \mathrm{kPa}$. In each method, the pressure was changed after the cores attained equilibrium and weighed before subjecting them to the next matric potential. The time to equilibrate varied from $2 \mathrm{~d}$ at the higher tension $(-1$ to $-10 \mathrm{kPa})$ to $10 \mathrm{~d}$ at the lower tension $(-1500 \mathrm{kPa})$. Finally, the cores were oven-dried at $105^{\circ} \mathrm{C}$ for $4 \mathrm{~d}$ and reweighed to determine the water content on dry mass basis. Soil bulk density was also determined to convert the gravimetric soil-water content $\left(\mathrm{kg} \cdot \mathrm{kg}^{-1}\right)$ to volumetric water content $\left(\mathrm{m}^{3} \cdot \mathrm{m}^{-3}\right)$.

\section{Estimated values of soil-water content limits}

The regression equations developed by Hutson (1986) were used to estimate the soil-water content at $-1,-3,-10,-30,-100,-500$ and $-1500 \mathrm{kPa}$ (Eqs. (4) to (10) of Table 1).

These equations were developed based on 409 South African soil samples. To estimate the soil-water content at the corresponding matric potential the percentage of clay, silt, fine sand, and soil bulk density in $\mathrm{Mg} \cdot \mathrm{m}^{-3}$ was determined. These equations use the particle size classification of the South African Soil Classification System (Soil Classification Working Group, 1991). According to this classification, the average values between 100 and $300 \mathrm{~mm}$ soil depths are clay $40 \%$; silt $17 \%$; fine sand $43 \%$ and soil bulk density $1.354 \mathrm{Mg} \cdot \mathrm{m}^{-3}$.

The drained upper limit was calculated using the retentivity relationship:

$$
\theta=\left(-\Psi / 138 \times 10^{-6} \mathrm{kPa}\right)^{-0.0987}
$$

The constants used for the retentivity relationship are $a=138 \mathrm{x}$ $10^{-6} \mathrm{kPa}$ and $b=-10.13$ (Eq. (1)).

A matric potential of $-33 \mathrm{kPa}$ was used in Eq. (11) (Colman, 1947; Jamison and Kroth, 1958) and the lower limit was calculated using the regression equation at a soil matric potential of $-1500 \mathrm{kPa}$ (Richards and Weaver, 1943). The plant-available 


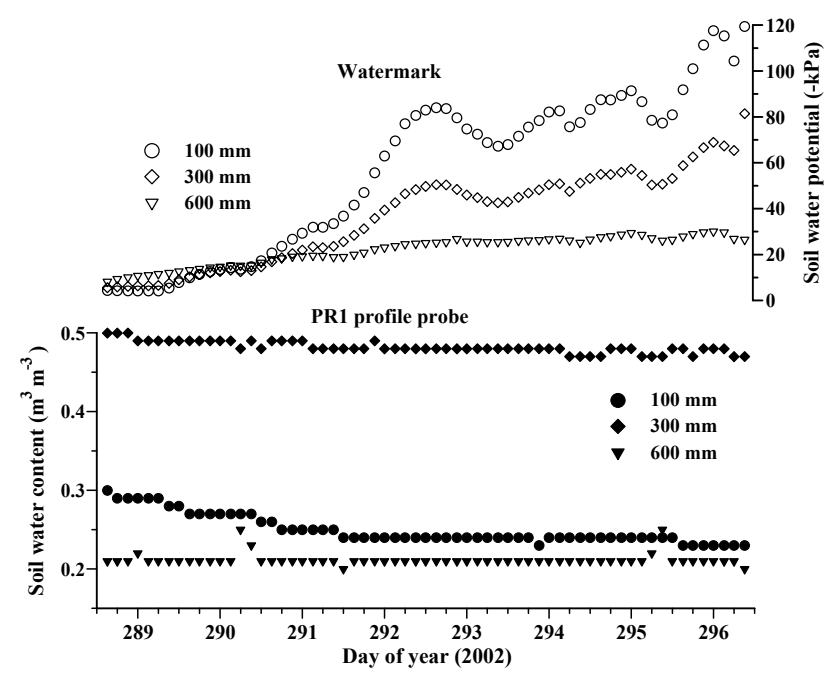

Figure 1

Field-measured soil-water content $\left(\mathrm{m}^{3} \cdot \mathrm{m}^{-3}\right)$ using a PR1 profile probe (lowest set of three curves) and soil-water potential ( $\mathrm{kPa}$ ) measured using Watermark sensors at three depths (upper set of three curves)

water (PAW) was then calculated from the difference between the drained upper and lower limits.

\section{Results and discussion}

\section{Field measurements}

The field-measured PR1 profile probe soil-water content and Watermark soil-water potential at 100,300 and $600 \mathrm{~mm}$ soil depths for the $1 \mathrm{~m}^{2}$ plot are shown in Fig. 1. The temporal soilwater content variation was between 0.30 and $0.23 \mathrm{~m}^{3} \cdot \mathrm{m}^{-3}$ at the first $100 \mathrm{~mm}$ soil depth with a corresponding soil-water potential of -4 to $-119 \mathrm{kPa}$. At this depth, soil-water content generally decreased due to evaporation and redistribution. Even though there were cover crops (oats, rye and rye grass) around the plot, there were not many plant roots to extract water from this depth. At the $300 \mathrm{~mm}$ depth, soil-water content varied between 0.50 and $0.47 \mathrm{~m}^{3} \cdot \mathrm{m}^{-3}$, corresponding to a soil-water potential between -5 and $-81 \mathrm{kPa}$. This small change in soil-water content could be due to the high clay content of the soil but it could also be due to the fact that there were no plant roots to extract the soil water. In clay soils, since the pore-size distribution is more uniform, more of the water is adsorbed, so that increasing the matric potential causes a more gradual decrease in soil-water content (Hillel, 1971). The soil at the $600 \mathrm{~mm}$ soil depth has a low soilwater content compared to that at the shallower depths since the applied water did not reach this depth. The soil-water content was almost constant at around $0.21 \mathrm{~m}^{3} \cdot \mathrm{m}^{-3}$ at the soil potential of -8 to $-30 \mathrm{kPa}$.

The field-measured soil-water content and soil-water potential values were compared with the results obtained by Schmidt and Schulze (1989) for the Cedara catchments. They calculated the PAW in the laboratory from the difference of the soil-water content at -33 and $-1500 \mathrm{kPa}$ matric potentials. They obtained different ranges of soil-water content at -33 and $-1500 \mathrm{kPa}$. The lowest soil-water content varied between 0.26 and $0.23 \mathrm{~m}^{3} \cdot \mathrm{m}^{-3}$ at -33 and $-1500 \mathrm{kPa}$ matric potentials respectively. The largest soil-water content ranged between 0.43 and $0.24 \mathrm{~m}^{3} \cdot \mathrm{m}^{-3}$ at -33 and $-1500 \mathrm{kPa}$ matric potentials respectively. Considering that these measurements were made

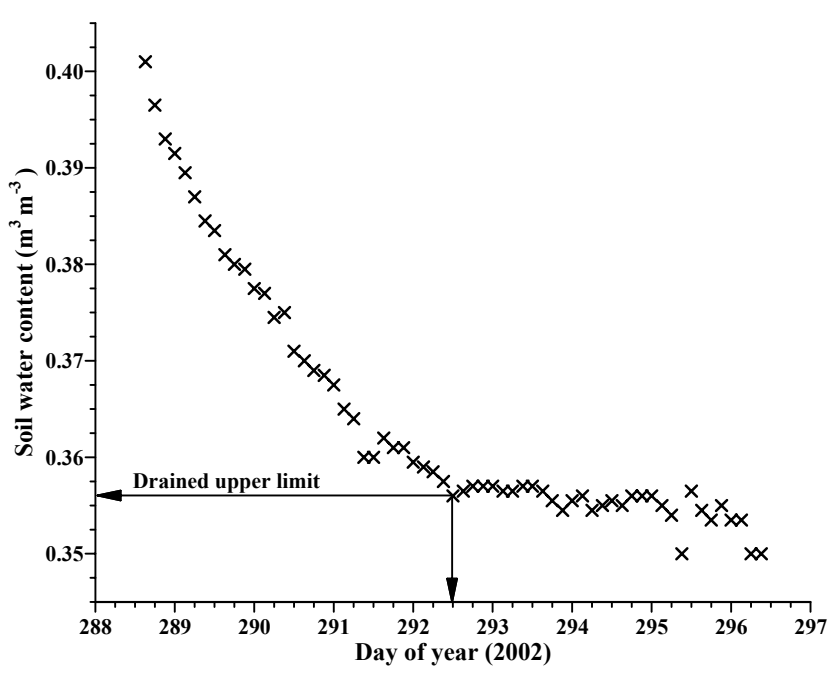

Figure 2

PR1 profile probe soil-water content vs. day of year after flooding the plot to determine the drained upper limit of the soil between the 100 and $300 \mathrm{~mm}$ soil depths

\begin{tabular}{|c|c|}
\hline \multicolumn{2}{|c|}{$\begin{array}{c}\text { TABLE } 2 \\
\text { Retentivity function calculated } \\
\text { soil-water content at certain } \\
\text { points of soil-water potential }\end{array}$} \\
\hline $\begin{array}{c}\text { Soil-water potential } \\
(-\mathrm{kPa})\end{array}$ & $\begin{array}{c}\text { Field-measured } \theta \\
\left(\mathrm{m}^{3} \cdot \mathrm{m}^{-3}\right)\end{array}$ \\
\hline 1 & 0.415 \\
\hline 5 & 0.391 \\
\hline 10 & 0.381 \\
\hline 33 & 0.365 \\
\hline 50 & 0.359 \\
\hline 100 & 0.350 \\
\hline 500 & 0.329 \\
\hline 1000 & 0.321 \\
\hline 1500 & 0.316 \\
\hline
\end{tabular}

in the laboratory at a wider range of soil-water potential (-33 to $-1500 \mathrm{kPa}$ ), the field-measured soil-water content values obtained using the PR1 profile probe and soil-water potential measurements obtained using the Watermark sensors were reasonable when compared with the results of Schmidt and Schulze (1989).

The values of the PR1 profile probe soil-water content and Watermark soil-water potential were averaged for the 100 and $300 \mathrm{~mm}$ soil depths to determine the drained upper limit and extrapolated to determine the lower limit since the soil-water potential did not reach $-1500 \mathrm{kPa}$ in the field. The drained upper limit was $0.355 \mathrm{~m}^{3} \cdot \mathrm{m}^{-3}$ for the $300 \mathrm{~mm}$ soil depth. This value was taken as the soil-water content when the decrease in soil-water content at this depth was negligible (Fig. 2). The lower limit was inferred as corresponding to a matric potential of $-1500 \mathrm{kPa}$ (Table 2) using the retentivity relationship:

$$
\theta=\left(-\Psi / 54 \times 10^{-12} \mathrm{kPa}\right)^{-0.0372}
$$

The constants for the retentivity relationship $a=54 \times 10^{-12} \mathrm{kPa}$ and $b=-26.88$ (Eq. (1)) were calculated from the graph of $\ln \theta$ vs. $\ln (-\Psi)$. 


\begin{tabular}{|c|c|c|}
\hline \multicolumn{3}{|c|}{ 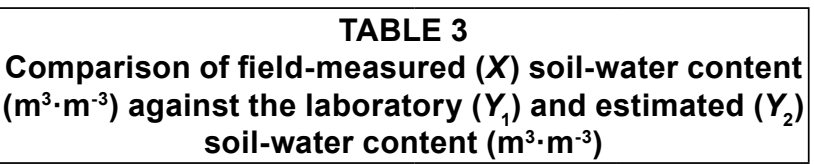 } \\
\hline Statistical parameters & $\begin{array}{c}\text { Laboratory- } \\
\text { measured } \\
\left(Y_{1}\right)\end{array}$ & $\begin{array}{c}\text { Estimated } \\
\text { values } \\
\left(\mathrm{Y}_{2}\right) \\
\end{array}$ \\
\hline $\mathrm{N}$ & 9 & 9 \\
\hline$r^{2}$ & 0.975 & 0.995 \\
\hline RMSE & 0.064 & 0.035 \\
\hline $\mathrm{P}(\mathrm{T} \leq \mathrm{t})$ two-tail $(95 \%)$ & 0.011 & 0.0005 \\
\hline Slope & 1.563 & 2.118 \\
\hline Intercept & -0.179 & -0.472 \\
\hline Standard error of $\mathrm{Y}$ on $\mathrm{X}$ & 0.009 & 0.006 \\
\hline SE slope & 0.094 & 0.059 \\
\hline Slope confidence limit 99\% & $1.234,1.892$ & $1.912,2.324$ \\
\hline Slope confidence limit 95\% & $1.341,1.785$ & $1.978,2.257$ \\
\hline SE intercept & \begin{tabular}{l|l}
0.060 \\
\end{tabular} & 0.037 \\
\hline Intercept confidence limit 99\% & $-0.2979,-0.061$ & $-0.603,-0.341$ \\
\hline Intercept confidence limit 95\% & $\mid-0.2595,-0.099$ & $-0.561,-0.384$ \\
\hline
\end{tabular}

The PAW was then equal to $0.039 \mathrm{~m}^{3} \cdot \mathrm{m}^{-3}$ or $3.9 \%$. Schmidt and Schulze (1989) calculated the PAW for the Cedara catchments to be between 2.67 and $19.8 \%$.

The drained upper limit $\left(0.355 \mathrm{~m}^{3} \cdot \mathrm{m}^{-3}\right)$ determined in the field (Fig. 2), when the soil-water content decrease was negligible, was close enough to the drained upper limit $\left(0.365 \mathrm{~m}^{3} \cdot \mathrm{m}^{-3}\right)$ estimated using the retentivity relationship at a soil-water potential of $-33 \mathrm{kPa}$. This result agreed with the estimation of the drained upper limit at a soil-water potential of $-33 \mathrm{kPa}$, which was proposed by Colman (1947) and Jamison and Kroth (1958). Other workers have also proposed different drained upper matric potentials with satisfactory results. For example, Hanks et al. (1954) used -20 kPa, Haise et al. (1955) used -10 kPa and Russel and Balcerek (1944), MacLean and Yager (1972) and Mottram et al. (1981) used $-5 \mathrm{kPa}$ to estimate the drained upper limit values. These variations in matric potential depend on soil texture. For example, sandy soils reach the drained upper limit at $-6 \mathrm{kPa}$, loamy sand at $-10 \mathrm{kPa}$, silt loams at $-30 \mathrm{kPa}$ and clay soils at -60 kPa (Water Resource Publications, 1964).

\section{Laboratory measurements}

The average soil-water content $(\theta)$ and soil-water potentials $(\Psi)$ at the rooting depth (100 to $300 \mathrm{~mm}$ ) were used to estimate the drained upper limit and lower limit values of the soil. From the laboratory measurements, the drained upper limit was 0.39 $\mathrm{m}^{3} \cdot \mathrm{m}^{-3}$ at $-33 \mathrm{kPa}$ and the lower limit was $0.31 \mathrm{~m}^{3} \cdot \mathrm{m}^{-3}$ at -1500 $\mathrm{kPa}$. The PAW was then calculated to be $0.08 \mathrm{~m}^{3} \cdot \mathrm{m}^{-3}$ (or $8 \%$ ).

The statistical analysis (Table 3 ) showed that the laboratory measurement of soil-water content was statistically different from the corresponding field-measured soil-water content at a given soil-water potential. From the result of the paired $t$-test it was found that the probability level $(\mathrm{P}=0.011)$ was lower than the critical alpha value $(\alpha=0.05)$, which indicated that there were significant differences between the two means at the $95 \%$ level of significance. The slope and intercept of the regression line were also statistically different from one and zero respectively (Table 3), which demonstrated that the soil-water content measurement in the laboratory was not a perfect estimation of the field measurement. The laboratory-measured soil-water content showed a bias (Fig. 3) with a systematic error of $94.6 \%$.

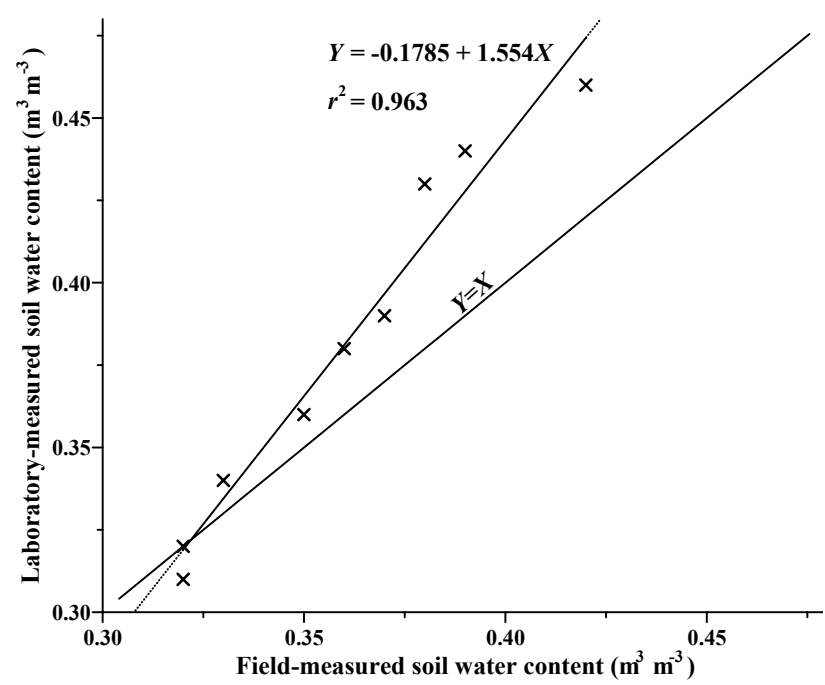

Figure 3

Laboratory-measured soil-water content $\left(\mathrm{m}^{3} \cdot \mathrm{m}^{-3}\right) \mathrm{vs}$. field-measured soil-water content $\left(\mathrm{m}^{3} \cdot \mathrm{m}^{-3}\right)$ at the same soil-water potential

When the laboratory-estimated drained upper limit values were compared with the field-measured drained upper limit values, the laboratory measurement over-estimated the drained upper limit value by $0.045 \mathrm{~m}^{3} \cdot \mathrm{m}^{-3}$. This result agreed with the conclusion made by Ratliff et al. (1983) that the laboratory estimates of the drained upper limit value obtained at $-33 \mathrm{kPa}$ water contents were significantly more than the field-measured drained upper limit. However, the laboratory estimate of the lower limit $\left(0.312 \mathrm{~m}^{3} \cdot \mathrm{m}^{-3}\right)$ obtained at $-1500 \mathrm{kPa}$ matric water potential was almost equal to the field-measured lower limit $\left(0.316 \mathrm{~m}^{3} \cdot \mathrm{m}^{-3}\right)$. This result agreed with the experimental result of Savage et al. (1996). They found that the choice of the $-1500 \mathrm{kPa}$ soil-water potential was appropriate and corresponded closely to the field lower limit of soil-water availability.

The retentivity relationship for the laboratory measurement (Eq. (13)) was developed to estimate the soil-water content for a given soil-water potential:

$$
\theta=\left(-\Psi / 3.94 \times 10^{-6} \mathrm{kPa}\right)^{-0.0588}
$$

The constants for the retentivity relationship $a=3.94 \times 10^{-6} \mathrm{kPa}$ and $b=-17.01$ were calculated from the slope and intercept of the graph $\ln \theta v_{s} \ln (-\Psi)$ (Fig. 4) using Eqs. (2) and (3).

\section{Estimated values of soil-water content limits}

The soil-water content was estimated for the respective soilwater potentials based on the Hutson (1986) regression equations and a comparison was made between the soil-water content limits of field-measured and laboratory-measured values. Using the regression equations, the drained upper limit was $0.295 \mathrm{~m}^{3} \cdot \mathrm{m}^{-3}$ at $-33 \mathrm{kPa}$ and the lower limit was $0.210 \mathrm{~m}^{3} \cdot \mathrm{m}^{-3}$ at $-1500 \mathrm{kPa}$. The PAW was therefore $0.085 \mathrm{~m}^{3} \cdot \mathrm{m}^{-3}$. The drained upper limit was under-estimated by $0.06 \mathrm{~m}^{3} \cdot \mathrm{m}^{-3}$ and 0.095 $\mathrm{m}^{3} \cdot \mathrm{m}^{-3}$ from the field-measured and laboratory-measured values respectively. The lower limit was also under-estimated by $0.11 \mathrm{~m}^{3} \cdot \mathrm{m}^{-3}$ and $0.099 \mathrm{~m}^{3} \cdot \mathrm{m}^{-3}$ from the field and laboratory measurements respectively.

From the statistical analysis (Table 3 ) the estimated soilwater content measurements were statistically different $(\mathrm{P}<\alpha)$ and biased (systematic error $=97 \%$ ) from the corresponding 

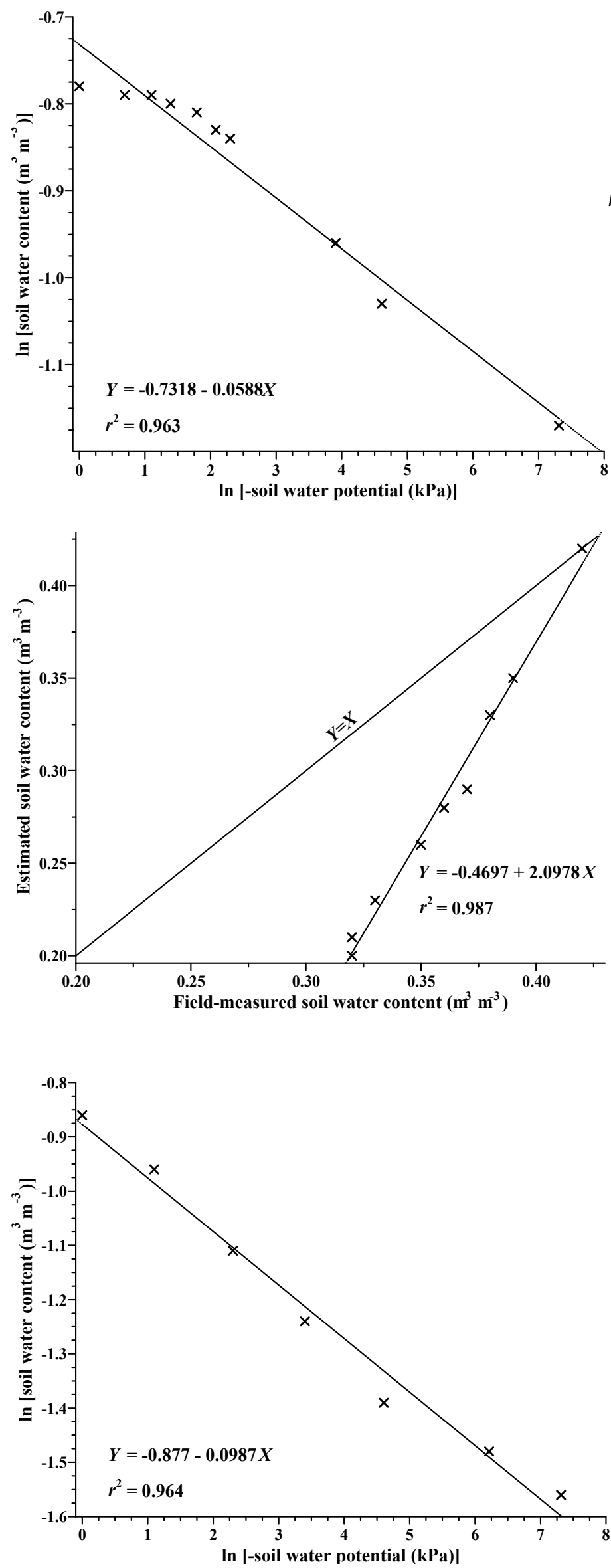

Figure 6

Estimated soil-water content (In $\theta)$ vs. the known soil-water potential (In (- $\Psi)$ ) fitted to develop the linear regression field-measured soil-water content at a given soil-water potential (Fig. 5). The slope and intercept were also statistically different from one and zero respectively. However, the relationship is highly significant (linear regression coefficient of determination of 0.995) and the slope and intercept were used as the multiplier and offset to adjust the equation to adequately estimate the soil-water content at the corresponding soilwater potentials.

The retentivity relationship for the estimated values (Eq. (11)) was developed to estimate values of soilwater content at a given soil-water potential. The constants $a$ and $b$ (Eq. (1)) were calculated using the graph $\ln \theta v s \ln (-\Psi)$ (Fig. 6).

\section{Conclusions}

The results obtained using laboratory and estimated soil-water content values demonstrate statistical differences from the soil-water content measured in the field. The variation in soil-water content was mainly due to the difference between the measurement methods, but in part the difference is also due to soil variability and the treatment of the soil sample between the time when the samples were taken from the field and laboratory measurement. With great care, laboratory measurements could yield a good estimation of soil-water content limits, if the errors encountered in the field and in the laboratory were minimized. Practically, it is relatively simple and feasible with the available sensors to measure the drained upper limit in the field. However, it is much more difficult to measure the lower limit in the field with the readily available sensors since the soil-water potential limit of $-1500 \mathrm{kPa}$ may not be reached. In such situations, the best option is to measure the lower limit in laboratory. The use of regression equations, which allow soil-water content estimates using some easily measurable soil parameters, could be useful for estimating the soil-water content limits when the time, cost and labour needed to undertake the field and laboratory measurements are considered. The regression equations that were developed by Hutson (1986) showed a linear regression coefficient of determination of 0.995 with systematic error of $97 \%$. If the 
equation was calibrated against the gravimetric soil-water content at the corresponding soil-water potential, it could yield a good estimate of soil-water content.

In this study, the drained upper limit and lower limit were defined using the laboratory-measured values of soil-water content at -33 and $-1500 \mathrm{kPa}$. However, many workers do not recommend the laboratory method, if direct measurement in the field is possible. The laboratory-measured values were taken, since the soil-water content was measured within the matric potential range from saturation to $-1500 \mathrm{kPa}$. In the field, measurements were made from -4 to $-119 \mathrm{kPa}$ at a soil depth of $100 \mathrm{~mm},-5$ to $-81 \mathrm{kPa}$ at $300 \mathrm{~mm}$ and -8 to $-30 \mathrm{kPa}$ at $600 \mathrm{~mm}$. The drained upper limit $\left(0.39 \mathrm{~m}^{3} \cdot \mathrm{m}^{-3}\right)$ and the lower limit $\left(0.31 \mathrm{~m}^{3} \cdot \mathrm{m}^{-3}\right)$, which was equal to $0.08 \mathrm{~m}^{3} \mathrm{~m}^{-3}$ resulted in the PAW value of $0.08 \mathrm{~m}^{3} \cdot \mathrm{m}^{-3}$. The upper and lower limits could then be used for monitoring the soil-water content using a soil-water content profile probe to determine the timing and amount of irrigation.

\section{Acknowledgements}

We acknowledge the assistance of the late Prof. MA Johnston (Soil Science, University of Natal) in the initial phases of this work. We acknowledge the assistance given by Ms. S Bezuidenhout and Mr. N van Rij (Crop Protection Section) of the Department of Agriculture and Environmental Affairs, Cedara in the field work and support from Ms. Jothimala Manickum, Mr. Peter Dovey, Mr. Essack Abib and Mr. Tad Dorasamy of the University of KwaZulu-Natal. Funding from the University of KwaZulu-Natal, the Water Research Commission and the World Bank in agreement with the Human Resources Development of the University of Asmara, Eritrea for this research is gratefully acknowledged.

\section{References}

ARMSTRONG CF, FLETCHER LIGON JT and McLEOD MF (1987) Automated system for detailed measurement of soil-water potential profiles using Watermark brand sensors. Proc. Int. Conf. on Measurement of Soil and Plant Water Status. Centennial of Utah State University, Logan, USA. 201-206.

BROOKS RH and COREY AT (1964) Hydraulic properties of porous media. Hydrology Paper No 3. Colorado State University, Fort Collins, USA.

CASSEL DK and KLUTE A (1986) Water potential: Tensiometry. In: Campbell GS, Jackson RD, Mortland MM, Nielsen DR and Klute A (eds.) Methods of Soil Analysis. Part 1: Physical and Mineralogical Methods. Agronomy Monograph No. 9 ( $2^{\text {nd }}$ edn.) 563-596. Am. Soc. Agron. Inc., Madison, Wisconsin, USA.

COLMAN EA (1947) A laboratory procedure for determining the field capacity of field soils. Soil Sci. 63 277-283.

COSBY BJ, HORNBERGER GM, CLAPP RB and GINN TR (1984) A statistical exploration of the relationships of soil moisture characteristics to the physical properties of soils. Water Resour. Res. $\mathbf{2 0}$ 680-690.

GARDNER WR, HILLEL D and BENYAMINI Y (1970) Post-irrigation movement of soil water: I Predistribution. Water Resour. Res. 6 851-861.

GEBREGIORGIS MF and SAVAGE MJ (2006) Determination of the timing and amount of irrigation of three winter cover crops with the use of dielectric constant and capacitance soil water content profile methods. S. Afr. J. Plant Soil. 23 (3).
GUPTA SC and LARSEN WE (1979) Estimating soil water retention characteristics from particle size distribution, organic matter content, and bulk density. Water Resour. Res 15 1633-1635.

HAISE HR, HAAS HJ and JENSEN LR (1955) Soil moisture studies on some great plain soils: Field capacity as related to $1 / 3$-atmosphere percentage, and 'minimum point' as related to 15 -atmosphere percentages. Soil Sci. Soc. Am. Proc. 19 20-25.

HANKS RJ, HOLMES WE and TANNER CB (1954) Field capacity approximation based on the moisture-transmitting properties of the soil. Soil Sci. Soc. Am. Proc. 18 252-254.

HILlEL D (1971) Soil and Water: Physical Principles and Processes. Academic Press, New York, USA.

HUTSON JL (1986) Water retentivity of some South African soils in relation to particle size criteria and bulk density. S. Afr. J. Plant Soil 3 151-155.

JAMISON VC and KROTH EM (1958) Available soil moisture storage capacity in relation to textural composition and organic matter content of several Missouri soils. Soil Sci. Soc. Am. Proc. 22 189-192.

JOVANOVIC NC and ANNANDALE JG (1997) A laboratory evaluation of Watermark electrical resistance and Campbell Scientific-299 heat dissipation matric potential sensors. Water SA 23 227-232.

LUKANGU G, SAVAGE MJ and JOHNSTON MA (1999) Use of subhourly soil water content measured with a frequency-domain reflectometer to schedule irrigation of cabbages. Irrig. Sci. 19 7-13.

LUKANU G and SAVAGE MJ (2006) Calibration of a frequencydomain reflectometer for determining soil-water content in a clay loam soil. Water SA 32 (1) 37-42.

MACLEAN AH and YAGER TU (1972) Available water capacities of Zambian soils in relation to pressure plate measurements and particle size analysis. Soil Sci. 113 23-29.

MOTTRAM R, HUTSON JL and GOODMAN PS (1981) Water retention of some Natal soils as related to soil texture and organic matter. Crop Prod. 10 47-50.

RATLIFF LF, RITCHIE JT and CASSEL DK (1983) A survey of fieldmeasured limits of soil water availability as related to laboratorymeasured properties. Soil Sci. Soc. Am. J. 47 750-775.

RAWLS WJ and BRAKENSIEK DL (1982) Estimating soil water retention from soil properties. J. Irrig. Drain. Div. ASCE 108 166-171.

RICHARDS LA and WEAVER LR (1943) Fifteen atmosphere percentages as related to the permanent wilting percentage. Soil Sci. 56 331-339.

RITCHIE JT (1981) Soil water availability. Plant Soil 58 327-338.

RITCHIE JT, GERAKIS A and SULEIMAN A (1999) Simple model to estimate field-measured soil water limits. Am. Soc. Agric. Eng. Proc. 42 (6) 1609-1614.

RUSSEL EW and BALCEREK W (1944) The determination of the volume and air space of soil clods. J. Agric. Sci. 34 123-132.

SALTER PJ and HAWORTH F (1961) The available-water capacity of a sandy loam soil I. A critical comparison of methods of determining the moisture content of soil at field capacity and the permanent wilting percentage. J. Soil Sci. 12 326-334.

SAVAGE MJ, RITCHIE JT, BLAND WL and DUGAS WA (1996) Lower limit of soil water availability. Agron. J. 88 644-651.

SAXTON KE, RAWLS WJ, ROMBERGER JS and PAPENDICK RI (1986) Estimating generalized soil-water characteristics from texture. Soil Sci. Soc. Am. J. 50 1031-1036.

SCHMIDT EJ and SCHULZE RE (1989) The Cedara Hydrological Research Catchments 1974 to 1989 . University of Natal, Dept. Agric. Eng. Rep. No 34, Pietermaritzburg, South Africa.

SCHULZE RE, HUTSON JL and CASS A (1985) Hydrological characteristics and properties of soil in southern Africa. 2. Soil retention models. Water SA 11 129-136.

SOIL CLASSIFICATION WORKING GROUP (1991) Soil Classification: A Taxonomic System for South Africa. The Department of Agricultural Development, Pretoria.

WATER RESOURCE PUBLICATIONS (1964) Soil-Plant-Water Relationships. National Engineering Publications, United States Soil Conservation Service, Colorado, USA. 
Available on website http://www.wrc.org.za ISSN 0378-4738 = Water SA Vol. 32 No. 2 April 2006 ISSN $1816-7950=$ Water SA (on-line) 